\section{A new era in the control of tuberculosis}

Enrico Girardi, ${ }^{1}$ Giuseppe Ippolito ${ }^{2}$

${ }^{1}$ Clinical Epidemiology Unit and ${ }^{2} O f f i c e$

of the Scientific Director, National Institute for Infectious Diseases L. Spallanzani, Rome, Italy

In the last two decades of the twentieth century, the world faced an unexpected resurgence of tuberculosis. Favored by the dismantling of control interventions in rich, low incidence countries, by the overburden on national Tuberculosis Programs in resource-poor countries and by the HIV/AIDS pandemic, the number of persons affected and the number of deaths due to tuberculosis started to rise. At the same time, multi drug-resistant tuberculosis emerged as a global problem. ${ }^{1}$ This led the World Health Organization (WHO) in 1993 to declare tuberculosis as a global emergency. ${ }^{2}$

Since then much has been achieved towards the ambitious goals set in 2000 by the World Health Assembly in the context of the Millennium Development Goals. Tuberculosis mortality in 2014 was $47 \%$ lower than in 1990 ,the target to halt and reverse tuberculosis incidence has been achieved globally and in $\mathbf{1 6}$ of the 22 high-burden countries and worldwide tuberculosis incidence was $18 \%$ lower than in 2000. Nonetheless, it has been estimated that in 2014 still 9.6 million people had tuberculosis and 1.5 million died of tuberculosis. ${ }^{3}$ Clearly, renewed efforts are needed if we want to move from a goal of containing the global tuberculosis epidemic to the possibility of terminating it. ${ }^{4}$ In this context, Infectious Disease Reports has asked to scientists and public health experts, who took part in an International Meeting held at the National Institute for Infectious Diseases L. Spallanzani in Rome, Italy, on the occasion of the 2015 World TB Day, to provide an up-date of current strategies and tools and of the research perspective in the field tuberculosis.

The paper of Raviglione and Sulis ${ }^{5}$ summarizes the challenges that we are going to face in the next future to move along the path delineated by the new strategy that was first launched in 2014 by WHO and that has shifted the focus from stopping to ending the tuberculosis epidemic. ${ }^{4}$

Progress in tuberculosis biomarkers will be essential to support evaluation of new thera- peutic strategies, in designing new approaches to vaccine, in targeting prevention interventions. However, progress in this field has been slow so far. ${ }^{6}$ Goletti et al. ${ }^{7}$ remind us that numerous candidate biomarkers continue to appear on the horizon, and that their validation against clear clinical endpoints in different populations will be an important challenge in the next future

Research of new tools for rapid microbiological diagnosis of tuberculosis and epidemiological characterization of circulating Mycobacterium tuberculosis strains will be one of the main components of innovation needed to improve management and control of tuberculosis as pointed out in the paper by Cannas et al. ${ }^{8}$

The area of tuberculosis treatment has seen no significant advancements for almost half a century. However, two drugs belonging to new classes of antimycobacterial agents were approved and released in 2012 and 2013 and more drugs are in the development pipeline. In addition, the paper by Gualano et al. reports that repurposing of existing drugs and designing and testing new, possibly shorter and simpler regimens, are being actively pursued. ${ }^{9}$

Finally, in the context of globalization and increasing magnitude of population movements, the issue of tuberculosis in migrants needs to be addressed in particular for low incidence countries. ${ }^{10}$ In this context an important contribution may come from active case finding interventions such as those carried out in Italy and summarized in the paper by Sañé Schepisi et al. ${ }^{11}$

\section{References}

1 Malin AS, McAdam KP. Escalating threat from tuberculosis: the third epidemic. Thorax 1995;50:S37-42.

2. World Health Organization. TB: a global emergency, WHO report on the TB epidemic. Available from: http://apps.who.int/iris/bitstream/10665/58 749/1/WHO_TB_94.177.pdf

3. World Health Organization. Global tuberculosis report. 2015. Available from: http://apps.who.int/iris/bitstream/10665/19 1102/1/9789241565059_eng.pdf?ua=1

4. World Health Organization. WHO end TB strategy. 2014. Available from: http://www.who.int/tb/post2015_strategy/e n/. Accessed: May, 2016.
Correspondence: Enrico Girardi, Clinical Epidemiology Unit, National Institute for Infectious Diseases L. Spallanzani - IRCCS, Via Portuense 292, 00149 Rome, Italy.

Tel +39.06.55170901.

E-mail: enrico.girardi@inmi.it

Key words: Tuberculosis.

Contributions: the authors contributed equally.

Conflict of interest: the authors declare no potential conflict of interest.

Received for publication: 15 June 2016. Accepted for publication: 15 June 2016.

This work is licensed under a Creative Commons Attribution-NonCommercial 4.0 International License (CC BY-NC 4.0).

(C) Copyright E. Girardi and G. Ippolito, 2016 Licensee PAGEPress, Italy

Infectious Disease Reports 2016; 8:6644

doi:10.4081/idr.2016.6644

5. Raviglione M, Sulis G. Tuberculosis 2015: burden, challenges and strategy for control and elimination. Infect Dis Rep 2016;8:6570.

6. Wallis RS, Maeurer M, Mwaba P. Tuberculosis-advances in development of new drugs, treatment regimens, hostdirected therapies, and biomarkers. Lancet Infect Dis 2016;16:e34-46.

7. Goletti D, Petruccioli E, Joosten SA, Ottenhoff THM. Tuberculosis biomarkers: from diagnosis to protection. Infect Dis Rep 2016;8:6568.

8. Cannas A, Mazzarelli A, Di Caro A, et al. Molecular typing of Mycobacterium tuberculosis strain: a fundamental tool for tuberculosis control and elimination. Infect Dis Rep 2016;8:6567.

9. Gualano G, Capone S, Matteelli A, Palmieri F. New antituberculosis drugs: from clinical trial to programmatic use. Infect Dis Rep 2016;8:6569.

10. Pareek M, Greenaway C, Noori T, et al. The impact of migration on tuberculosis epidemiology and control in high-income countries: a review. BMC Med 2016;14:48.

11 Sañé Schepisi M, Gualano G, Piselli P, et al. Active tuberculosis case finding interventions among immigrants, refugees and asylum seekers in Italy. Infect Dis Rep 2016;8:6594. 